\title{
STRUKTUR UKURAN DAN HUBUNGAN PANJANG BERAT IKAN HASIL TANGKAPAN PADA RUMPON PORTABLEDAN RUMPON TRADISIONAL DI PERAIRAN ACEH BARAT
}

\author{
Catch Lenght Weight Relationship Around Portable and Tradisional FADs \\ In Aceh Barat Waters \\ Oleh: \\ Jaliadi $^{*}$, Roza Yusfiandayani², Mulyono S Baskoro² \\ ${ }^{1}$ Mahasiswa Program Pascasarjana Departemen PSP FPIK IPB \\ ${ }^{2}$ Departemen PSP FPIK IPB \\ *Korespondensi: jaliadi.tesis@gmail.com
}

\begin{abstract}
ABSTRAK
Penangkapan ikan telah memberikan konstribusi terhadap peningkatan ekonomi nelayan yang cukup memadai khususnya di wilayah Meulaboh. Semakin meningkatnya kegiatan penangkapan ikan dapat mengalami penurunan stok ikan pada rumpon, namun hal ini akan berdampak negatif terhadap populasi dan pola pertumbuhan dari segi panjang berat ikan. Tujuan penelitian ini untuk mengetahui pola pertumbuhan ikan yang tertangkap di sekitar rumponportable dan rumpon tradisional. Data yang dikumpulkan berupa data primer yang merupakan hasil pengukuran panjang dan berat ikan selama 30 trips, kemudian data dianalisis secara deskriptif. Hasil penelitian menunjukkan panjang cagak ikan di sekitar rumpon portableikan tongkol krei (Auxis thazard) dominasi ukuran panjang berkisar antara 24,5-27,5 cmFL dan 34,5-27,5 cmFL, ikan layang (Decapterus russelli) ukuran panjang antara 14,5-17,5 cmFL, ikan ekor kuning (Alepes djadaba) ukuran panjang antara 14,5-17,5 cmFL, ikan selar kuning (Selaroide leptolepis) ukuran panjang antara 14,5-17,5 cmFL. Hubungan panjang berat ikan pada rumpon portable dengan persamaan ikan tongkol krei $\mathrm{W}=0,0089 \mathrm{FL} 3,1293$, ikan layang $\mathrm{W}=0,0068 \mathrm{FL} 3,1414$, ikan ekor kuning $\mathrm{W}=0,0178 \mathrm{FL} 2,8953$, ikan selar kuning $\mathrm{W}=$ $0,0113 F L 3,0829$. Hubungan panjang beratpada rumpon tradisional dengan persamaan ikan tongkol krei $\mathrm{W}=0,0112 \mathrm{FL} 3,0513$, ikan layang $\mathrm{W}=0,011 \mathrm{FL} 2,9588$, ikan ekor kuning $\mathrm{W}=0,0632 \mathrm{FL} 2,4025$, ikan selar kuning $\mathrm{W}=0,0256 \mathrm{FL} 2,7779$.
\end{abstract}

Kata kunci:hubungan panjang berat, rumpon portable dan rumpon tradisional, periran Aceh Barat

\section{ABSTRACT}

Fishing has contributed to the economic improvement of fishermen adequate, especially in the region of Meulaboh. The increasing fishing activities can decrease fish stocks on FADs, and this will give a negative impact on the population and the growth pattern in terms of length weight of the fish. The purpose of this study was to determine the growth pattern of the fish that caught around portable FADs and traditional FADs. Data that collected is a primary data which is the result of the measurement of length and weight of the fish in 30 trips, then the data were analyzed descriptively numerically. The results showed that the fish that caught around FADs are frigate tuna, Indian scad, yellow tail fish, and yellow trevally fish. The forked length of fish around portable FADs are a round of 24.5 to $27.5 \mathrm{~cm}$ and 34.5 to $27.5 \mathrm{~cm}$ for frigate tuna (Auxis thazard), 14.5 to $17.5 \mathrm{~cm}$ for Indian Scad (Decapterus russelli) 14.5 to $17.5 \mathrm{~cm}$ for yellow tail fish (Alepes djadaba), and 14.5 to $17.5 \mathrm{~cm}$ for yellow trevally fish (Selaroides leptolepis). Lengthweight of relationship fish that caught around the portable FADs are $W=0,0089 F L 3,1293$ for frigate tuna $W=0,0068 F L 3,1414$ for indian scad $W=$ 0,0178FL2,8953 for yellow tail fish, and $W=0,0113 F L 3,0829$ for yellow trevally fish. Lengthweight of relationship fish that caught around the traditional foods are $W=0,0112 F L 3,0513$ for frigate tuna 
$W=0,011 F L 2,9588$ for Indian scad $W=0,0632 F L 2,4025$ for yellow tail fish, and $W=0,0256 F L 2,7779$ for yellow trevally fish.

Keywords: lengthweight relationship of portable and traditional FADs, Aceh Barat waters

\section{PENDAHULUAN}

Aceh Barat yang memiliki panjang garis pantai 50,55 km dengan luas perairan lautnya $80,88 \mathrm{~km}^{2}$ dengan berbagai variasi ekosisstem memiliki hasil tangkapan ikan laut yang beragam. Kabupaten Aceh Barat merupakan wilayah pesisir yang kaya akan hasil perikanannya. Hal tersebut tidak terlepas dari letaknya yang menghadap langsung Samudera Hindia yang kaya akan ikan (Diana et al, 2010).Penangkapan ikan telah memberikan kon-tribusi terhadap peningkatan ekonomi nelayan yang cukup memadai khususnya di wilayah Meulaboh. Intensitas penangkapan yang tinggi saat ini cenderung mengabaikan kelestarian sumberdaya ikan.

Kegiatan penangkapan ikan di perairan Aceh Barat menggunakan alat bantu rumpon sebagai pengumpul ikan. Rumpon atau Fish Aggregating Device(FAD) menurut Peraturan Menteri Kelautan dan Perikanan Republik Indonesia Nomor 71/Permen-Kp/2016 adalah alat bantu pengumpul ikan yang menggunakan berbagai bentuk dan jenis pemikat/atraktor yang berfungsi untuk memikat ikan agar berkumpul dan lebih mudah dalam melakukan penangkapan ikan.

Pemanfaatan hasil tangkapan pada rumpon untuk memudahkan kegiatan operasi penangkapan ikan pada rumpon yang dipasang di laut, baik laut dangkal maupun laut dalam. Rumpon tradisional pada umumnya terbuat dari pelepah daun kelapa atau rongsokan becak yang ditenggelamkan. Jenis rumpon tradisional ini umumnya hanya menggunakan satu atraktor dan cenderung memiliki selektivitas target yang rendah. Daya tahan rumpon tradisional juga terbatas seperti daun kelapa yang cepat lapuk dan terbawa oleh arus laut (IMI 2012).

Rumpon portable merupakan pengembangan dari rumpon konvensional yang menggunakan konsep respon ikan terkait suatu frekuensi suara pada atraktor. Rumpon portable lebih fleksibel dalam pengoperasiannya, dimana rumpon dapat dilakukan di berbagai tempat dan waktu. Pengoperasiaan rumpon portable tidak dilakukan secara menetap melainkan dapat berpindah lokasi sesuai dengan daerah penangkapan yang diinginkan. Ketika tidak digunakan, rumpon tersebut dapat dibawa dan dipindahkan kedaerah lain atau disimpan hingga dilakukan operasi penangkapan ikan selanjutnya (Yusfiandayani et al. 2013).

Semakin meningkatnya kegiatan penangkapan ikan dapat mengalami penurunan stok ikan pada rumpon, namun hal ini akan berdampak negatif terhadap populasi dan pola pertumbuhan dari segi panjang dan berat ikan. Menurut Effendie (1997) beberapa faktor yang mempengaruhi pola pertumbuhan ikan diantaranya adalah faktor dalam dan faktor luar yang mencakup jumlah dan ukuran makanan yang tersedia, suhu, oksigen terlarut, faktor kualitas air, umur, dan ukuran ikan serta matang gonad. Penelitian ini bertujuan untuk menganalisiskisaran panjang dan hubungan panjang berat ikan yang tertangkap pada rumpon portable dan rumpon tradisional di perairan Aceh Barat Meulaboh.

\section{METODOLOGI}

\section{Waktu dan Tempat Penelitian}

Penelitian dilakukan pada bulan Juli sampai bulan Agustus 2016 di perairan Aceh Barat Meulaboh. Peta lokasi penelitian dapat dilihat pada Gambar 1.

\section{Metode Pengumpulan Data}

Datadikumpulkan berupa data primer.Pengumpulan data pimer melalui pengamatan secara langsung dengan metode experimental fishingpada rumpon portable dan rumpon tradisional, penangkapan ikan dilakukan sebanyak 30 trip dalam waktu 


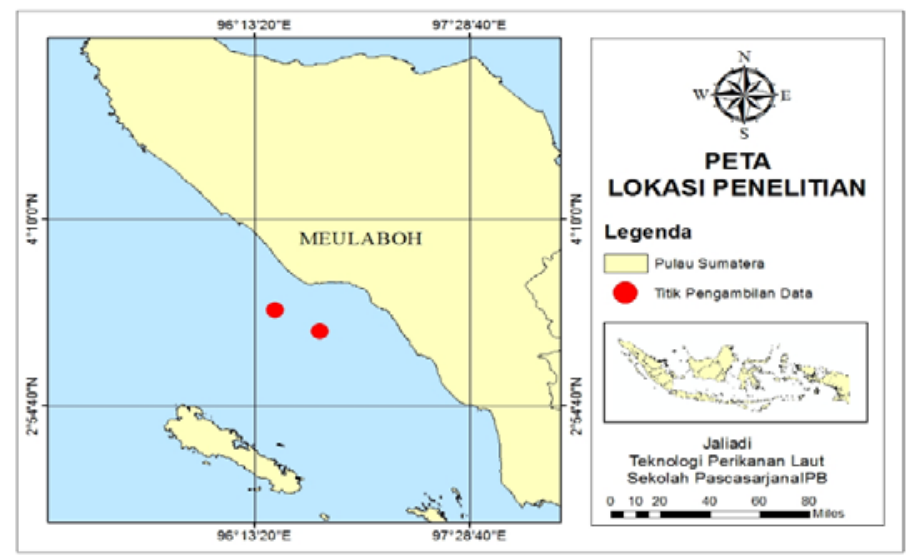

Gambar 1 Peta Lokasi Penelitian

bersamaanpada rumponportabledan rumpon tradisional

untuk mengetahui jumlah hasil tangkapannya. Kapal yang digunakan untuk pengambilan data sebanyak 2 unit yang merupakan kapal pancing ulur yang sering digunakan nelayan untuk menangkap ikan pada rumpon. Selanjutnya dilakukan pengambilan data panjang dan berat ikan yang tertangkap pada rumpon portable dan rumpon tradisional. Pengukuran panjang cagak (fork length, FL) dilakukan meng-gunakan meteran gulung dengan panjang maksimum 5 meter, bobot ikan diukur menggunakan timbangan digital 3 $\mathrm{kg}$.

\section{Analisis Data}

Data hasil tangkapan di tabulasikan menggunakan program MS. Office excel 2010 dan kemudian dianalisis secara deskriptif. Pendekatan ini bertujuan untuk mengkaji kisaran panjang hasil tangkapan. Ukuran selang kelas ikan pada rumpon portable dan rumpon tradisional di hitung mengunakan rumus distribusi frekuensi (Walpole 1995).

$$
\begin{aligned}
& \mathrm{K}=1+3.32 \log \mathrm{n} \ldots \ldots \\
& i=\frac{\mathrm{N} \max -\mathrm{N} \text { min }}{K}
\end{aligned}
$$

Keterangan :

$$
\begin{array}{ll}
K & =\text { Jumlah kelas } \\
n & =\text { Banyak data } \\
i & =\text { Selang kelas } \\
N \max & =\text { Nilai terbesar dan } \\
N \min & =\text { Nilai terkecil }
\end{array}
$$

Hubungan panjang-berat menggunakan moodel allometric linear di gunakan untuk menghitung parameter a dan b melalui pengukuran berat dan panjang menurut DeRobertis and William (2008) dengan persamaan:

$$
\mathrm{W}=\mathrm{a} \mathrm{L}^{\mathrm{b}}
$$

Keterangan :

$$
\begin{array}{ll}
\mathrm{W} & =\text { bobot } \\
\mathrm{L} & =\text { panjang } \\
\mathrm{a} \text { danb } & =\text { konstanta }
\end{array}
$$

Nilai b sebagai penduga hubungan antara panjang dan berat dengan kriteria:

Nilai $b=3$, ikan memiliki pola pertumbuhan isometrik (pertambahan bobot seimbang dengan pertambahan panjang)

Nilai $\mathrm{b}>3$, ikan memiliki pola pertumbuhan allometrik positif (pertambahan bobot lebih besar dari pertambahan panjang)

Nilai $\mathrm{b}<3$, ikan memiliki pola pertumbuhan allometrik negatif (pertambahan bobot lebih kecil dari pertambahan panjang). Kemudian dilakukan uji-t pada tingkat kepercayaan 95\% (Steell and Torrie, 1989), data tersebut ditampilkan dalam bentuk tabel dan grafik.

\section{HASIL DAN PEMBAHASAN}

\section{Frekuensi Panjang Ikan}

Selama penelitian jumlah tangkapan pada rumpon portable sebanyak 472 ekor dan pada rumpon tradisional sebanyak 969 ekor. Ukuran panjang cagak cmFL (fork length) 
ikan yang tertangkap di sekitar rumpon portable jenis ikan tongkol krei di dominasi panjang cagak pada kisaran 24,5-27,5 cmFL dan rumpon tradisional panjang cagak pada cagak pada kisaran 14,5-17,5 cmFL, ikan ekor kuning pajang cagakpada kisaran 14,5-17,5 cmFL, ikan selar kuning panjang cagak pada kisaran 14,5-17,5cmFL, hal ini dapat dilihat

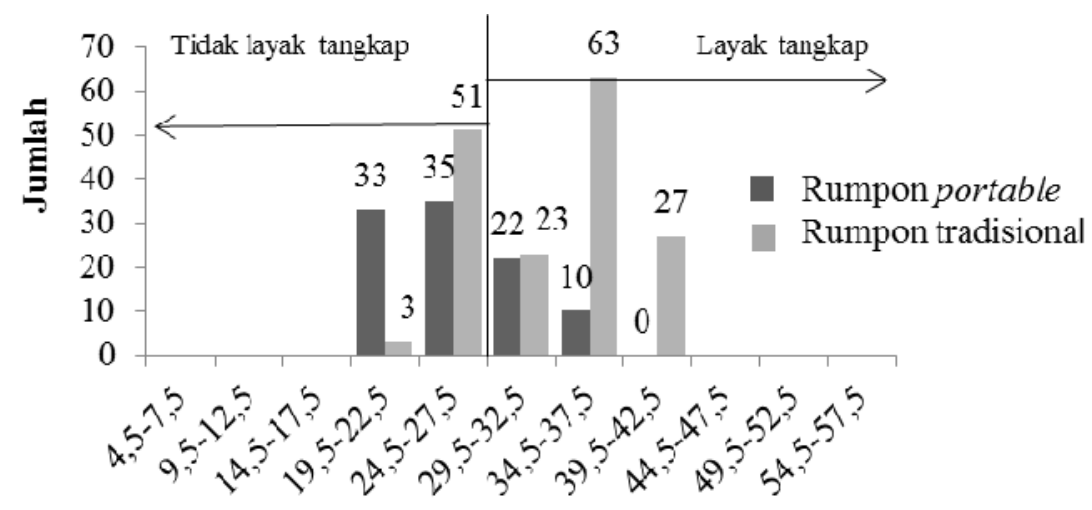

Kisaran panjang FL (cm)

Gambar 2 Sebaran panjang kelas ikan tongkol krei (Auxis thazard)

kisaran 34,5-37,5 cmFL, ikan layang panjang

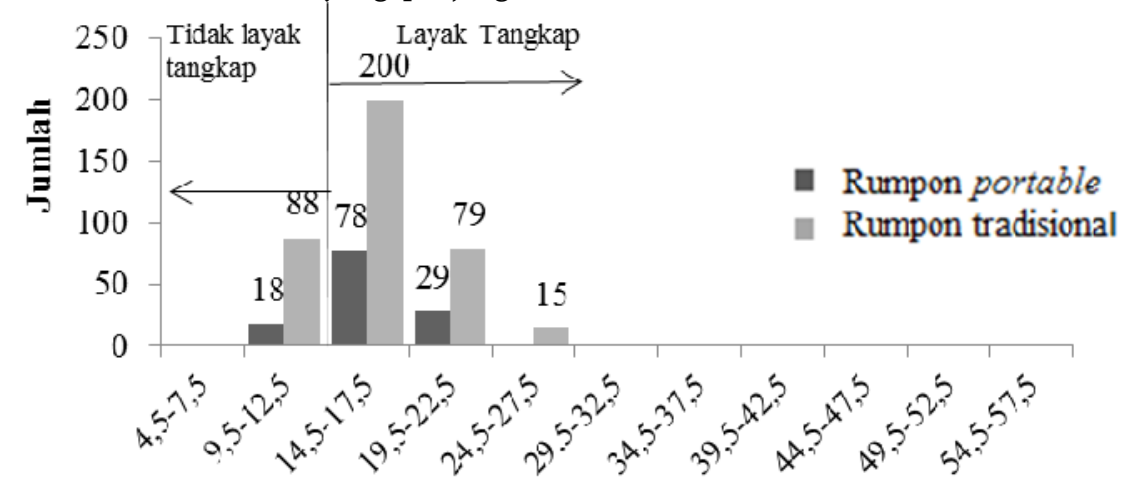

Kisaran panjang FL (cm)

Gambar 3 Sebaran panjang kelas ikan layang (Decapterus russelli)

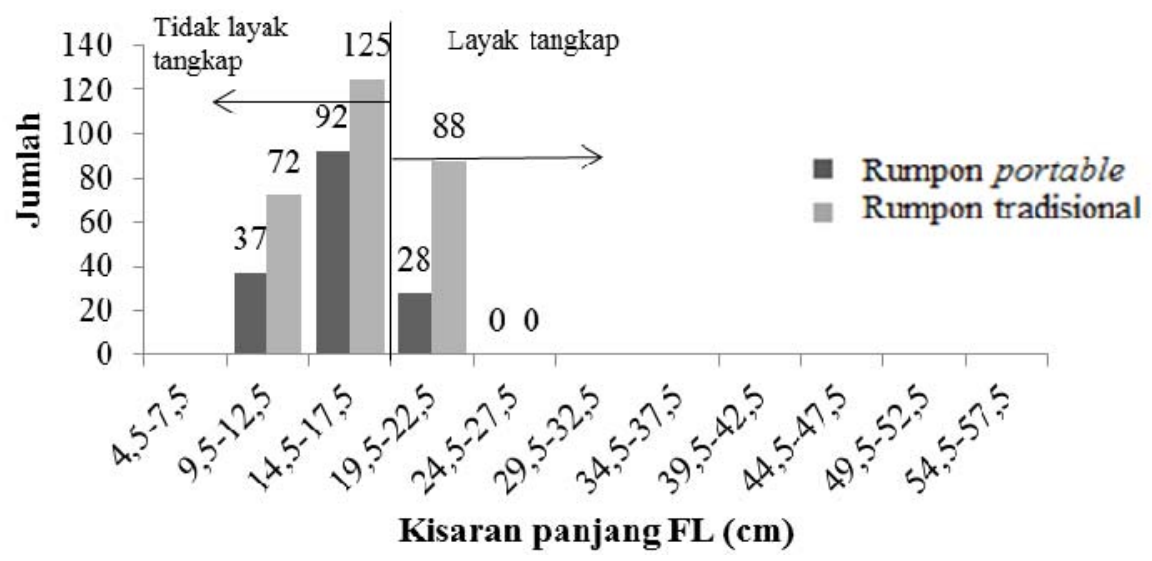

Gambar 4 Sebaran panjang kelas ikan ekor kuning (Alepes djadaba) 
ikan tongkol krei 67,7\%, ikan layang sebesar

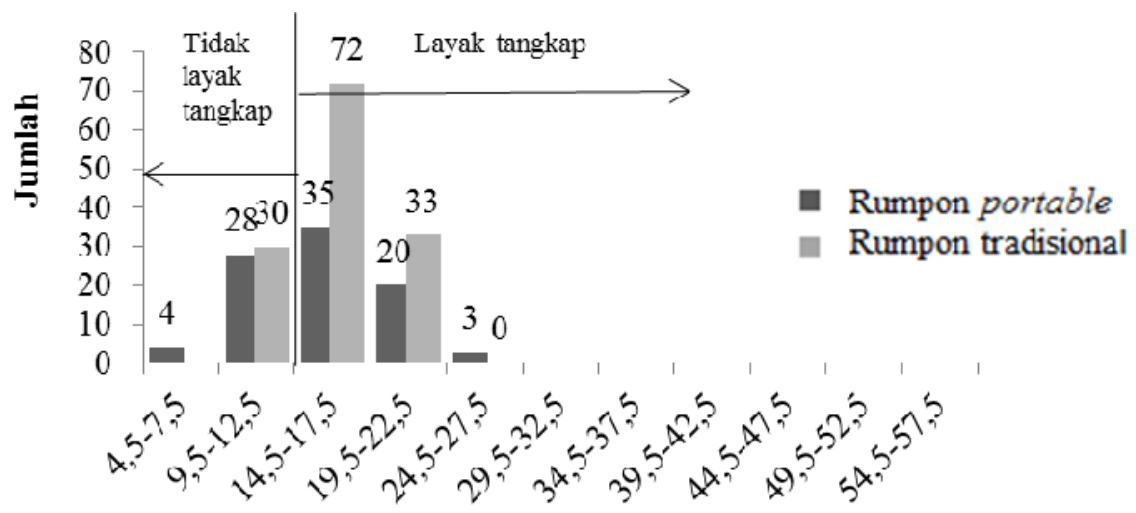

Kisaran panjang FL (cm)

Gambar 5 Sebaran panjang kelas ikan selar kuning (Selaroide leptolepis)

pada Gambar 2-5.

Length maturitydiperoleh dari berbagai sumber. Length maturityhasil tangkapan yang dominan tertangkappada rumpon portable dan rumpon tradisional dapat dilihat pada Tabel 1 .

Hasil pengukuran FL ikan yang tertangkap pada rumpon portable dan rumpon tradisional menunjukkan bahwa jumlah persentase ikan layak tangkap dan tidak layak tangkap. Adapun empat jenis ikan layak dan tidak layak tangkap dapat dilihat pada Gambar 6.

Berdasarkah hasil grafik diatas menunjukkan bahwa ikan layak tangkap yang dominan tertangkap pada rumpon portable adalah ikan tongkol krei layang sebesar 32,0\% ikan layang sebesar 85,6\%, ikan ekor kuning sebesar 17,8\% dan selar kuning sebesar 61,1\%. Ikan yang tidak layak tangkap jenis ikan tongkol krei sebesar 68,0\%, ikan layang sebesar 14,4\%, ikan ekor kuning sebesar 82,2\%, ikan selar kuning sebesar 39,9\%.

Ikan layak tangkap yang dominan tertangkap pada rumpon tradisional adalah
77,0\%, ikan ekor kuning sebesar 74,7 dan ikan selar kuning sebesar 77,8\%. Ikan yang tidak layak tangkap adalah ikan tongkol krei sebesar 32,2ikan layang sebesar 23,0\%, ikan ekor kuning sebesar 25,3\% dan ikan selar kuning sebesar 22,2\%.

\section{Hubungan Panjang BeratRumpon Portable dan Rumpon Tradisional}

Hubungan panjang berat ikan tongkol krei (Auxis thazard) disekitar rumpon portable dengan persamaanW $=0.0089 x^{3} L^{3,1293}$ dengan nilai koefesien $\quad \mathrm{R}^{2}=0,9995$, ikanlayang (Decapterus russelli)dengan persamaan $\mathrm{W}=0.0068 \times \mathrm{xL}^{3,1414}$ dengan koefesien $\mathrm{R}^{2}=0,9987$, ikan ekor kuning (Alepes djadaba) dengan per-samaan $\mathrm{W}=0,0178 \times \mathrm{xL}^{2,8953}$ dengan koefesien $\mathrm{R}^{2}=0,992$, ikan selar kuning (Selaroides leptolepis) dengan persamaan $\mathrm{W}=0,0256 \times \mathrm{FL}^{2,7779}$ dengan koefesien $\mathrm{R}^{2}=0,9854$

Hasil pengukuran hubungan panjangberat ikan yang dominan tertangkap disekitar rumpon tradisional, ikan tongkol krei (Auxis thazard) dengan persamaanW $=0,0112 \times \mathrm{FL}^{3,0513}$ dengan nilai

Tabel 1 Length maturityikan layak tangkap

\begin{tabular}{lcl}
\hline \multicolumn{1}{c}{ Jenis Ikan } & Length Maturity $(\mathrm{Lm})$ & \multicolumn{1}{c}{ Sumber } \\
\hline Tongkol Krei (Auxis thazard) & $29 \mathrm{~cm}$ & FAO 1983. \\
Layang (Decapterus ruselli) & $15,3 \mathrm{~cm}$ & Poojary et al 2015. \\
Ekor Kuning (Alepes djadaba) & $19 \mathrm{~cm}$ & Reje 1993. \\
Selar Kuning (Selaroide leptolepis) & $13,4 \mathrm{~cm}$ & Randall 1995.
\end{tabular}




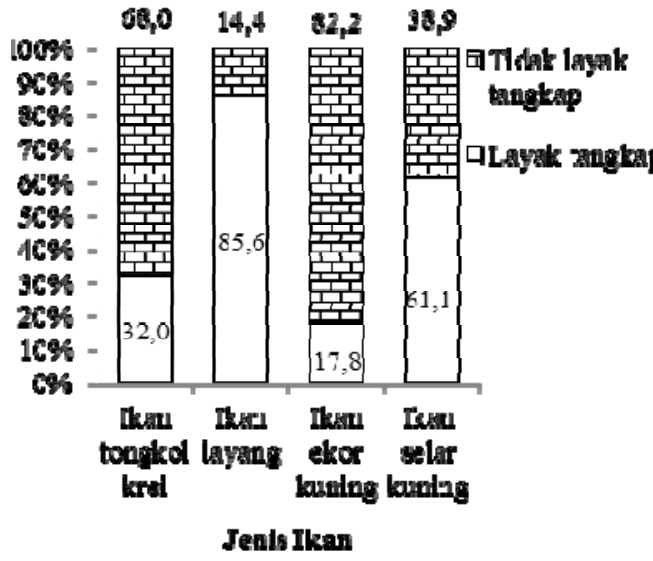

Rumpon portable

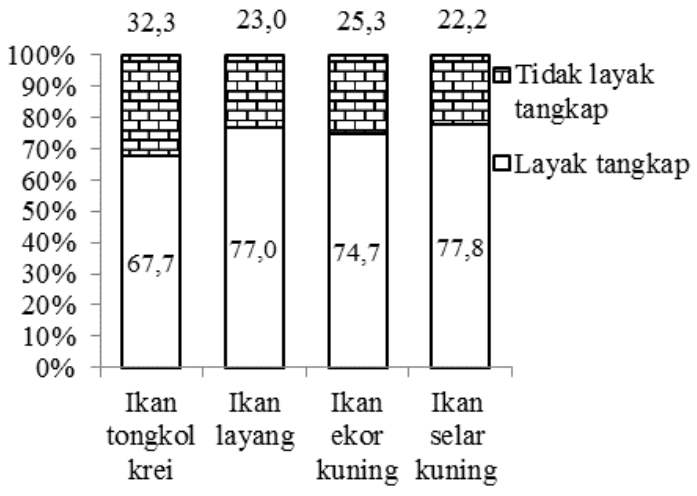

Jenis Ikan

Rumpon tradisional

Gambar 6 Jumlah persentase ikan layak tangkap dan tidak layak tangkap pada rumpon portable dan rumpon tradisional

koefesien $\mathrm{R}^{2}=0,9918$, ikanlayang (Decapterus russelli) dengan persamaan $\mathrm{W}=0,011 \mathrm{xFL}^{2,9588}$ dengan koefesien $\mathrm{R}^{2}=0,9421$,

ikan ekor kuning (Alepes djadaba) dengan persamaan $\mathrm{W}=0,0632 \times \mathrm{xL}^{2,4025-}$ dengan koefesien $\mathrm{R}^{2}=908$, ikan selar kuning (Selaroides leptolepis) dengan persamaan $\mathrm{W}=0,0113 \times \mathrm{xL}^{3,0829}$ dengan koefesien $\mathrm{R}^{2}=09886$, hal ini dapat dilihat pada Gambar 7-10.

Masyahoro (2009)memperlihatkan hubungan panjang berat ikan tongkol krei (Auxis thazard) dalam bentuk persamaan yaitu $\mathrm{W}=$ 3,63 FL-6,23 dengan nilai koefisien korelasi determinasi $\mathrm{R}^{2}=0,90$ menunjukkan bahwa 90\% variasi nilai berat ikan (W) dijelaskan oleh panjang cagak (FL), hal ini menunjukkan bahwa pola pertumbuhan ikan bersifat

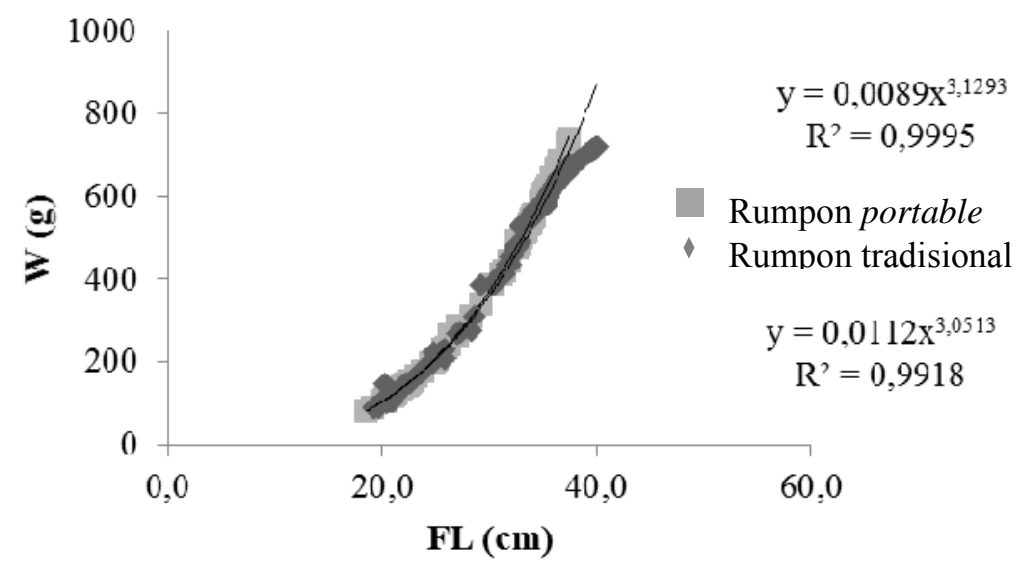

Gambar 7 Hubungan panjang berat Ikan Tongkol krei (Auxis thazard) allametrik positif. Menurut Palandri et al. (2008) mengatakan hasil tangkapan sebanyak 83 ekor menunjukkan pola pertumbuhan ikan tongkol krei bersifat allometrik positif.

Pola pertumbahan ikan layang memiliki pola pertumbahan allometrik positif dengan nilai b 2,933400-3,388204 (Manik 2009). Munurut Mulfizal et al. (2012) menyatakan bahwa secara umum nilai $b$ bergantung pada kondisi fisiologis dan lingkungan seperti suhu, salinitas, letak geografis dan teknik sampling dan juga kondisi biologis seperti per-kermbangan gonad dan ketersediaan makanan.Menurut Prihartini (2006) hasil perhitungan sampling dari Perairan Timur sebanyak 756 ekor.Decapterus russelli dengan kisaran panjang cagak (FL) $86 \mathrm{~mm}-214 \mathrm{~mm}$ dan 


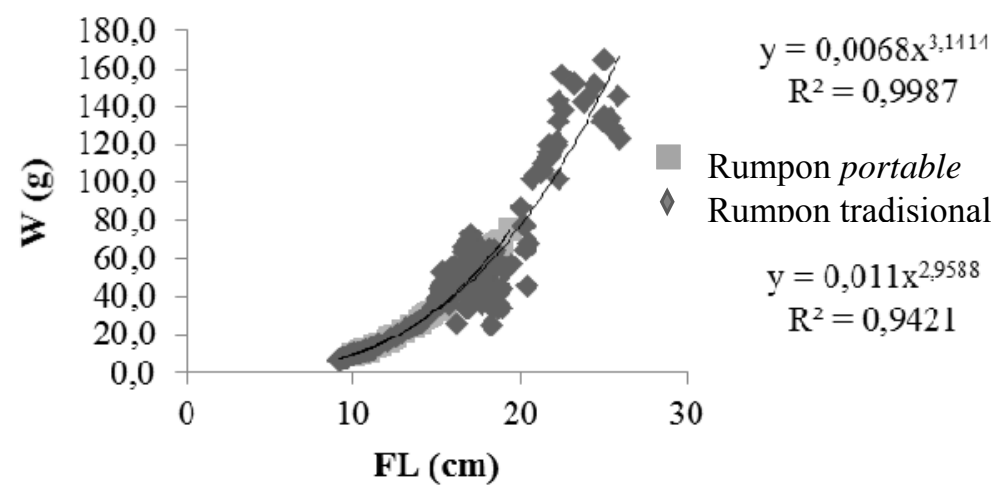

Gambar 8 Hubungan panjang berat ikan layang (Decapterus ruselli)

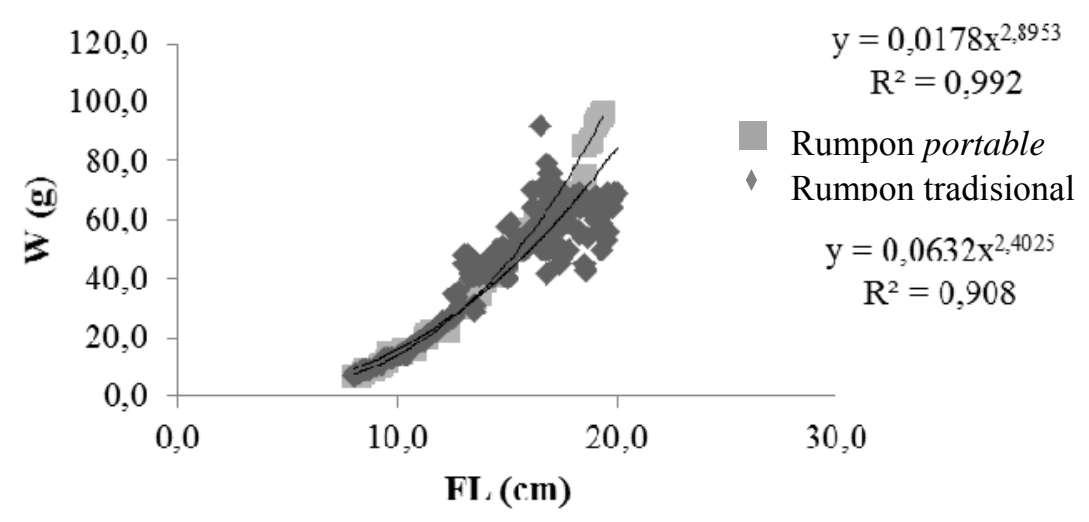

Gambar 9 Hubungan panjang berat ikan ekor kuning (Alepes djedaba)

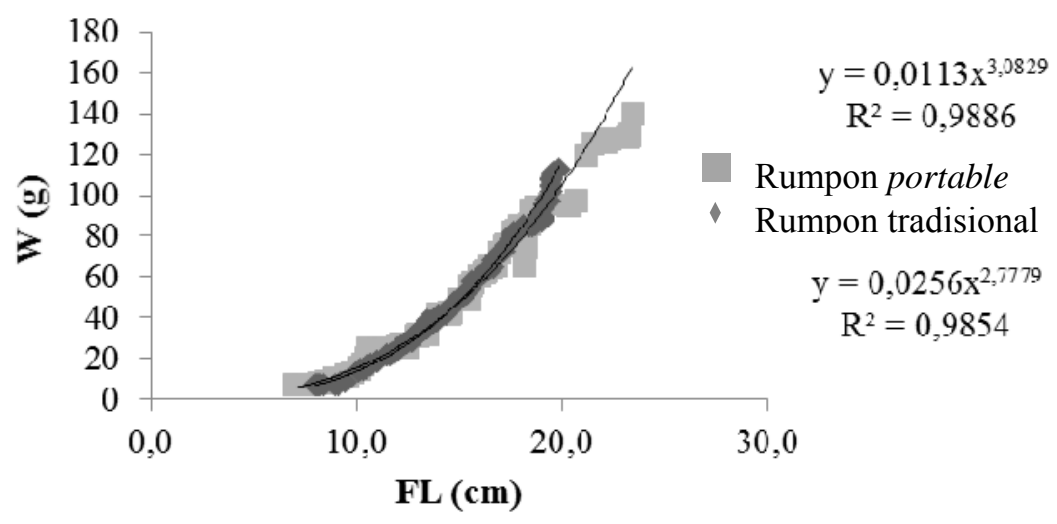

Gambar 10 Hubungan panjang berat Ikan Selar Kuning (Selaroides leptolepis)

kisaran berat 30,7-135,8 gram diperoleh nilai b yaitu 3,027 sehingga dapat dikatakan bahwa sifat pertumbuhan ikan layang di perairan ini bersifat isometrik.

Shuaib and Ayub (2011) mengatakan bahwa ikan ekor kuning (Alepes djedaba) yang didaratkan di Pelabuhan Karachi Fish Harbour memiliki persamaan $\mathrm{W}=2,153 \times \mathrm{FL}^{3,084}$, nilai $\mathrm{b}$ sebesar 3.084 adalah pola pertambahan panjang sebanding dengan pola pertambahan berat (isometrik), hal ini dapat dilihat pada nilai $\mathrm{R}^{2}$ sebaesar 0,891 artinya bahwa berat ikan ada kaitannya dengan panjang ikan sebesar 89,1\%.Rousefeell and Everhart (1962) mengatakan perhitungan panjang berat berdasarkan jumlah sampel yang diperoleh dengan nilai $\mathrm{n}=50$ dengan nilai $\mathrm{b}=3,123$. Menurut Lagler et al,(1977) mengatakan 
Tabel 2Hubungan panjang berat ikan menggunakan uji-t pada rumpon portable dan tradisional.

\begin{tabular}{|c|c|c|c|c|c|c|c|c|}
\hline Rumpon & Jenis ikan & $\mathrm{n}$ & $\mathrm{a}$ & $\mathrm{b}$ & $\mathrm{R}^{2}$ & T-hit & T-tab & Ket \\
\hline Portable & \multirow{2}{*}{$\begin{array}{l}\text { Tongkol krei } \\
\text { (Auxis thazard) }\end{array}$} & 100 & 0,0089 & 3,1293 & 0.9995 & 15,201 & 1,984 & $\mathrm{~A}+$ \\
\hline Tradisional & & 167 & 0,0112 & 3,0513 & 0.9918 & 24,270 & 1,973 & $\mathrm{~A}+$ \\
\hline Portable & \multirow{2}{*}{$\begin{array}{c}\text { Layang } \\
\text { (Decapterus } \\
\text { ruselli) }\end{array}$} & 125 & 0,0068 & 3,1414 & 0.9987 & 18,818 & 1,979 & $\mathrm{~A}+$ \\
\hline Tradisional & & 382 & 0,011 & 2,9588 & 0,9421 & 18,950 & 1,966 & A - \\
\hline Portable & \multirow{2}{*}{$\begin{array}{c}\text { Ekor kuning } \\
\text { (Alepes djedaba) }\end{array}$} & 157 & 0,0178 & 2,8953 & 0.992 & 17,025 & 1,975 & A - \\
\hline Tradisional & & 285 & 0,0632 & 2,4025 & 0,908 & 31,768 & 1,968 & A - \\
\hline Portable & \multirow{2}{*}{$\begin{array}{l}\text { Selar kuning } \\
\text { (Selaroide } \\
\text { leptolepis) }\end{array}$} & 90 & 0,0256 & 2,7779 & 0.9854 & 11,639 & 1,987 & A - \\
\hline Tradisional & & 135 & 0,0113 & 3,0829 & 0.9886 & 16,247 & 1,977 & $\mathrm{~A}+$ \\
\hline
\end{tabular}

Keterangan A- (Allometrik negatif), A+ (Allometrik positif).

bahwa nilai b pada ikan ekor kuning (Alepes djadaba) berfluktuasi antara 2,5-4 dan kebanyakan mendekati 3.

Hasil analisis hubungan panjang berat diketahui bahwa persamaan hubungan panjang berat ikan selar kuning (Selaroides leptolepis)adalah $\mathrm{W}=0,01138 \times \mathrm{xL}^{3.0829}$. Nilai b yang di-peroleh sebesar 3,0829 dan setelah dilakukan uji $\mathrm{t}(\alpha=0.05)$ terhadap nilai $\mathrm{b}$ diketahui bahwa ikan selar kuning memiliki pola pertumbahan alometrik positif, artinya pertambahan berat lebih cepat dari pada pertambahan panjang. Hal ini sesuai dengan yang disampaikan oleh Effendi (1997) dimana ikan dengan pola pertambahan allometrik positif apabila nilai $\mathrm{b}>3$. Hal ini dapat dilihat pada Tabel 2.

\section{KESIMPULAN}

1. Hasil tangkapan ikan yang dominan dan layak tangkapap pada rumpon portable jenis ikan layang sebesar $(85,6 \%)$ dan ikan selar kuning sebesar $(61,1 \%)$ dengan kisaran panjang ratarata 14,5-17,5 cm. Sedangkan pada rumpon tradisional jumlah ikan dominan dan layak tangkap jenis ikan tongkol krei sebesar $(67,7 \%)$ dengan kisaran panjang 34,5-37,5 cm, ikan layang (77,0\%), ikan ekor kuning $(74,7 \%)$ dan ikan selar kuning $(77,8 \%)$ dengan kisaran panjang rata rata $14,5-17,5 \mathrm{~cm}$.

2. Pola pertumbuhanikan yang dominan tertangkap pada rumpon portable danrumpon tradisional bersifat allometrik positif dan allometrik negatif.

\section{SARAN}

1. Daerah penangkapan ikan menggunakan rumpon portable dan rumpon tradisional $>20$ mil untuk menghasil tangkapan lebih besar.

2. Diperlukan penelitian lanjutan menggunakan rumpon portable untuk mengetahui jumlah tangkapan mi-nimal satu tahun.

3. Perlu dilakukan sistem pengakian dari atas kapal supaya rumpon portable tidak perlu di angkat pada saat pergantian baterei aki.

\section{DAFTAR PUSTAKA}

DeRobertA, William, K. 2008. Weight-legth relationship in fisheries studies: the standard allometric model should be applied with caution. Transaction of the American Fisheries Society, 137: 707-719. 
Diana F. Mahjali, S, Edwarsyah, Rozi, A. 2010. Rumpon Reef Piramit Sebagai Ekosistem Baru Biota Laut.Jurnal Ilmiah Pembangunan Aceh.Ceureumen 1 (1):11 - 23.

Effendie M.I. 1997. Biologi Perikanan. Yayasan Pustaka Nusatama. Yogyakarta. 163 hal.

FAO Species Catalogue. Vol. 2. Scombrids of the world. An annotated and illustrated catalogue of Tunas, Mackerels, Bonitos and related species known to date.Collette, B.B. and C.E. Nauen 1983. FAO Fish. Synop, (125)137 p.

IMI2012. Rumpon Elektronik, Buah Tangan IPB Untuk Nelayan. Indonesia Maritime Institute.

Lagler K.F. J. E. Bardach, R. R. Miller. D. R. M. Passino. 1977. Ichtiology. John Wiley and Sons, Inc. United State of America.

Manik N. 2009. Hubungan Panjang Berat dan Faktor Kondisi Ikan Layang (Decapterus russelli) dari Perairan Sekitar Teluk Likupang Sulawesi Utara. Oseanologi dan Limnologi di Indonesia. 35 $(1): 65-74$.

Masyahoro A. 2009. Model Simulasi Numerik Hubungan Panjang Berat Ikan Tongkol (Auxis thazard) pada Pangkalan Pendaratan Ikan Labuan Bajo Kabupaten Donggala. Jurnal Agroland 16 (3): 274 - 282.

Mulfizar AM, Zainal, Irma D. 2012. Hubungan panjang berat dan factor kondisi tiga jenis ikan yang tertangkap di perairan kuala gigieng, aceh besar, provinsi aceh. Jurnal Depik. 1(1): 1-9.

Palandri G, Lanteri L, Garibaldi F, Orsi Relini L (2009). Biological parameters of bullet tuna in the Ligurian Sea. Collect. Sci. Pap. ICCAT, 64(7): 2272-2279.

Peraturan Menteri Kelautan Dan Perikanan Republik Indonesia Nomor 71/Permen-Kp/2016. Jalur Penangkapan Ikan Dan Penempatan Alat Penangkapan Ikan di Wilayah Pengelolaan Perikanan Negara Republik Indonesia.

Poojary NL, R. Tiwari1 and Sujit Sundaram2015. Reproductive biology of the Indian scad, Decapterus russelli (Ruppell, 1830) from Maharashtra waters, northwest coast of India. doi: 10.6024/jmbai.57(1) 1-8.

Prihartini A. 2006. Analisis Tampilan Biologis Ikan Layang (Decapterus Sp) Hasil Tangkapan Purse Seine yang Didaratkan Di PPN Pekalongan. [Tesis]. Universitas Diponegoro semarang. 90 hal.

Randall JE. 1995. Coastal Fishes of Oman. University of Hawaii Press. Honolulu: University of Hawai i Press. p. 183.

Reje SG. 1993. Some aspects of biology of Alepes djedaba (Forsskal) from Veraval, Gujarat. Indian Journal of Fisheries 49(3): 189-192.

Ruonsefell GA, Everhart WH. 1962. Fishery Science its Methods and Aplications. New York : John Wiley and Sons. $444 \mathrm{hlm}$.

Shuaib N, Ayub Z, 2011. Length-Weight Relationship, Fecundity, Sex-ratio and Gonadal Maturation in shrimp scad, Alepes djedaba (Forsskal, 1775) landing at the Karachi Fish Harbour, Karachi, Pakistan. Centre of Excellence in Marine Biology, University of Karachi, Karachi-Pakistan. International Fisheries Symposium. Hal 10-16.

Steel R.G.D. dan Torrie, J.H. (1989). Prinsip dan Prosedur Statistika, Terjemahan: Ir. Bambang Sumantri, PT. Gramedia, Jakarta.

Walpole 1995. Pengantar Statistika. Gramedia Pustaka Utama. Jakarta.

Yusfiandayani R, Jaya I, Baskoro M.S. 2013. Uji Coba Penangkapan Pada Rumpon Portable Di Perairan Palabuhanratu. Jurnal Teknologi Perikanan dan Kelautan. 4(1): 89-98. 